\title{
Pathology of Marek's disease in layer chickens in Bangladesh
}

\author{
US Suma, MW Rahman, M Nooruzzaman, EH Chowdhury and MR Islam* \\ Department of Pathology, Faculty of Veterinary Science, Bangladesh Agricultural \\ University, Mymensingh-2202, Bangladesh
}

\begin{abstract}
We performed a pathological investigation of Marek's disease in commercial layer chickens in Bangladesh. A total of 23 dead or sick birds, suspected of Marek's disease, were obtained from 10 different layer farms of Mymensingh, Gazipur, Tangail and Pabna districts from March to November 2011. Lameness, torticollis and paralysis were characteristic clinical signs in the affected birds. At necropsy, diffuse enlargement or nodular lesions were found in the liver, spleen, proventriculus, heart, kidney, ovary and intestine. The highest number of tumours were in the proventriculus $(17 / 23)$ followed by liver $(13 / 23)$ and spleen $(8 / 23)$. No gross lesions were found in the nerve plexus. Histologically, lymphomatous lesions were observed. In the liver and kidney, diffuse proliferation of pleomorphic lymphocytes was associated with extensive damage of the parenchyma, while the lesions in the proventriculus and intestine were characterized by diffuse and focal and nodular proliferation of lymphocytes. The findings of the present study suggest that Marek's disease can be expected without obvious nervous lesions and the lymphomatous lesions could be diverse depending on the tissues involved. (Bangl. vet. 2017. Vol. 34, No. 2, 35 - 41)
\end{abstract}

\section{Introduction}

Marek's disease (MD) is a lymphoproliferative disease of poultry characterized by malignant T-cell lymphomas, paralysis, neurological disorders and profound immunosuppression (Davison and Nair, 2004; Jarosinski et al., 2006). The disease is caused by Marek's disease virus (MDV) belonging to the family Herpesviridae under the genus Mardivirus. MD is spread by the inhalation of contaminated poultry house dust and dander, where the virus can remain infectious for long periods (Schat and Nair, 2013). Affected birds remain infectious for life, continuously shedding the virus. MD has been successfully controlled by vaccination (Churchill et al., 1969; Rispens et al., 1972). However, the efficacy of MD vaccines is reduced by the evolution of MDV towards greater virulence (Witter et al., 1997). As a result, sporadic outbreaks of MD still cause significant economic losses.

During the early cytolytic phase of infection, MDV causes massive destruction of lymphocytes and macrophages, causing severe immuno suppression (Schat and Nair, 2013). The virus remains latent in the infected CD4+ and CD8+ T cells. From around 3-4 weeks, some of the latently infected CD4+ T cells are transformed, leading to the development of multiple lymphomas in visceral organs, resulting in mortality (Nair, 2018). Paralysis, due to the lymphoid infiltration of the peripheral nerves, also occurs

*Corresponding author:- E-mail: mrislam_bau@yahoo.com 
in some of these birds. Initially, MDV is transmitted from cell to cell, but later the virus moves to the feather follicle epithelial cells and sheds into the poultry house environment, acting as a source of infection to naïve birds (Jarosinski, 2017).

Marek's disease is prevalent in Bangladesh (Mosleuddin and Dewan, 1974), although there are few published reports. The diagnosis of MD is usually based on clinical presentation and gross lesions. Therefore, a detailed pathological investigation of MD from clinical outbreaks is necessary to understand the pathology of MD occurring in Bangladesh. Here, we performed a pathological investigation of 10 outbreaks of MD from commercial layer farms of Mymensingh, Tangail, Gazipur and Pabna districts of Bangladesh.

\section{Materials and Methods}

\section{Outbreak investigation}

A total of 23 layer chickens from 10 suspected outbreaks of Marek's disease were investigated. Chickens either sick or dead, suspected as Marek's disease cases, were collected from farms of Mymensingh, Tangail, Gazipur and Pabna districts from March to November 2011. All birds were reportedly vaccinated against Marek's disease at one-day-old with herpes virus of turkey (HVT) vaccine.

\section{Necropsy and sample collection}

The birds were brought to the Department of Pathology, Bangladesh Agricultural University. Necropsy was performed by a trained veterinarian, and gross lesions were recorded. For the molecular diagnosis of the disease, feather follicle samples were collected. Tissues from organs with grossly visible tumours or enlargement were collected in $10 \%$ neutral buffered formalin for histopathology.

\section{Molecular detection of Marek's disease virus}

For the confirmation of Marek's disease, DNA was extracted from feather follicle using the conventional phenol-chloroform-isoamylalcohol method. The extracted DNA was used to amplify 132 base pair (bp) tandem repeats in the internal repeat long region of the MDV genome using the primer pair Oligo 1 (5'TGCGATGAAAGTGCTATGGAGG-3') and Oligo 2 (3'-GAGAATCCCTATGAGAAA GCGC-5') as described by Silva (1992). PCR was carried out using the PCR Master Mix kit (Promega Corporation, WI, USA). The thermal profile was denaturation at $95^{\circ} \mathrm{C}$ for 2 minutes followed by 35 cycles of PCR, consisting of denaturation at $94^{\circ} \mathrm{C}$ for 1 minute, annealing at $55^{\circ} \mathrm{C}$ for 1 minute, extension for 3 minutes at $72^{\circ} \mathrm{C}$, followed by elongation for 5 minutes at $72^{\circ} \mathrm{C}$. Finally, the amplified products were subjected to electrophoresis using $1.4 \%$ agarose gel.

\section{Histopathology}

Formalin-fixed tissues were processed, embedded with paraffin, sectioned, and stained with haematoxylin and eosin (H\&E) following the standard protocol (Luna, 1968). 


\section{Results and Discussion}

\section{Clinical features and molecular diagnosis}

The age of the birds ranged from 8-35 weeks. The major clinical history as described by the farmers was regular mortality with emaciation. Lameness, torticollis and paralysis were characteristic clinical signs (Table 1). In PCR, feather follicles collected from all 10 Marek's disease outbreaks successfully amplified MDV DNA. On electrophoresis, strong bands of expected 185 and/or 317 bp were observed representing a single or two $132 \mathrm{bp}$ repeats, which indicated the presence of virulent MDV.

Table 1: Clinical history of outbreaks of Marek's disease in chickens

\begin{tabular}{|c|c|c|c|}
\hline Case No. & Bird type & Age & Clinical history \\
\hline 1 & Layer parent stock & $8 \mathrm{~W}$ & Regular mortality with emaciation \\
\hline 2 & Commercial layer & $15 \mathrm{~W}$ & Emaciated body, loss of appetite and lameness \\
\hline 3 & Commercial layer & $12 \mathrm{~W}$ & Emaciated body, loss of appetite and lameness \\
\hline 4 & Commercial layer & $30 \mathrm{~W}$ & Emaciated body, loss of appetite and lameness \\
\hline 5 & Commercial layer & $35 \mathrm{~W}$ & Emaciated body, loss of appetite and lameness \\
\hline 6 & Commercial layer & $12 \mathrm{~W}$ & $\begin{array}{c}\text { Regular mortality, emaciation, lameness and neck } \\
\text { twisting, anorexia }\end{array}$ \\
\hline 7 & Commercial layer & $9 \mathrm{~W}$ & Regular mortality with emaciation and lameness. \\
\hline 8 & Commercial layer & $30 \mathrm{~W}$ & $\begin{array}{l}\text { Regular mortality with emaciation, paralysis and } \\
\text { twisted neck }\end{array}$ \\
\hline 9 & Commercial layer & $17 \mathrm{~W}$ & Regular mortality, Emaciation and paralysis \\
\hline 10 & Commercial layer & $23 \mathrm{~W}$ & Regular mortality and emaciation \\
\hline
\end{tabular}

\section{Gross pathological changes}

The gross lesions in the affected birds are presented in Fig. 1(a-e). Diffuse enlargement or nodular lesions were found in the liver, spleen, proventriculus, heart, kidney, ovary and intestine. The affected livers were enlarged with rounded edges (Fig. 1a); multiple grey or yellow tumours were found in some cases. The spleen was enlarged (Fig. 1b) and contained whitish nodules in a few birds. The proventriculus was enlarged (Fig. 1c) and mucosa appeared to have irregular thickening. Lung samples were normal except for occasional consolidation. The intestine showed whitish multiple nodular growths visible from the serosal surface (Fig. 1d). The heartshowed diffuse or nodular whitish areas in the myocardium (Fig. 1e). Neoplastic growth in other organs including ovaries and skin was also observed. No gross lesions were observed in sciatic nerve plexus. 


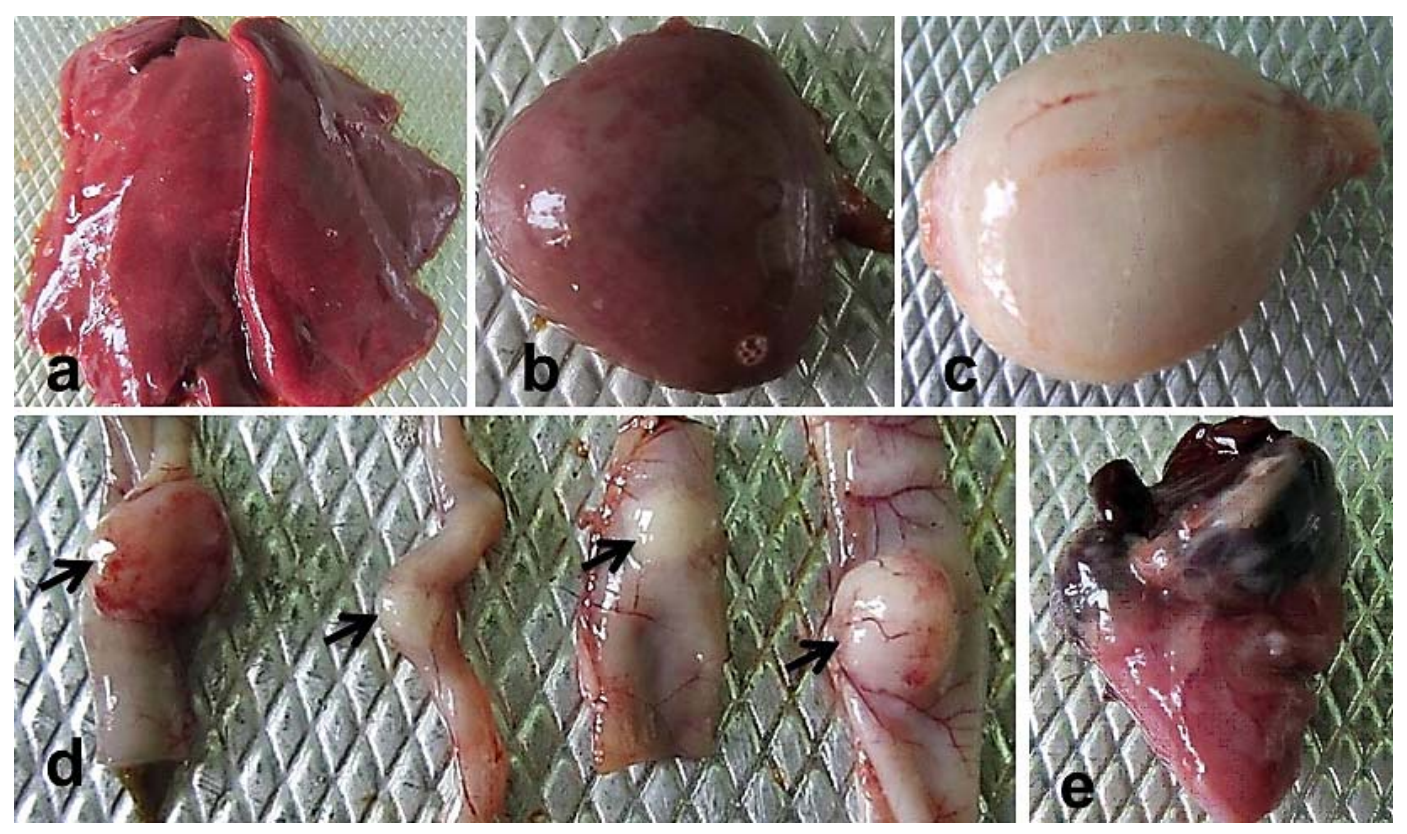

Fig. 1: Gross pathological changes in affected chickens showing (a) hepatomegaly, (b) splenomegaly, (c) thickened proventriculus, (d) tumours in intestine and (e) heart.

The distribution of tumours is shown in Table 2.The highest number of tumours was found in the proventriculus (17/23) followed by liver (13/23) and spleen $(8 / 23)$. Interestingly, no gross changes were observed in sciatic nerves or brachial nerves, although some birds show significant nervous signs.

Table 2: Distribution of grossly visible tumours in different organs of Marek's disease affected chickens

\begin{tabular}{l|c|c|c|c|c|c|c}
\hline \multirow{2}{*}{$\begin{array}{l}\text { Case } \\
\text { No. }\end{array}$} & \multirow{2}{*}{$\begin{array}{c}\text { No. of } \\
\text { birdsexamined }\end{array}$} & \multicolumn{7}{|c}{ No. of birds having tumours in } \\
\cline { 3 - 8 } & Liver & Spleen & Proventriculus & Heart & Ovary & Others* \\
\hline 1 & 5 & 3 & - & 5 & - & - & - \\
2 & 1 & 1 & 1 & 1 & - & - & - \\
3 & 2 & - & - & 2 & - & - & - \\
4 & 2 & - & - & - & - & 2 & - \\
5 & 2 & - & - & - & - & 1 & - \\
6 & 2 & 2 & 2 & - & - & - & 1 \\
7 & 3 & 2 & - & 3 & - & - & - \\
8 & 2 & 1 & 1 & 2 & - & - & 2 \\
9 & 2 & 2 & 2 & 2 & 2 & - & 1 \\
10 & 2 & 2 & 2 & 2 & 2 & - & 1 \\
\hline Total & $\mathbf{2 3}$ & $\mathbf{1 3}$ & $\mathbf{8}$ & $\mathbf{1 7}$ & $\mathbf{4}$ & $\mathbf{3}$ & $\mathbf{5}$ \\
\hline
\end{tabular}

*Tumour was also found in other organs like intestine, kidney and skin. "-“: No visible tumour 

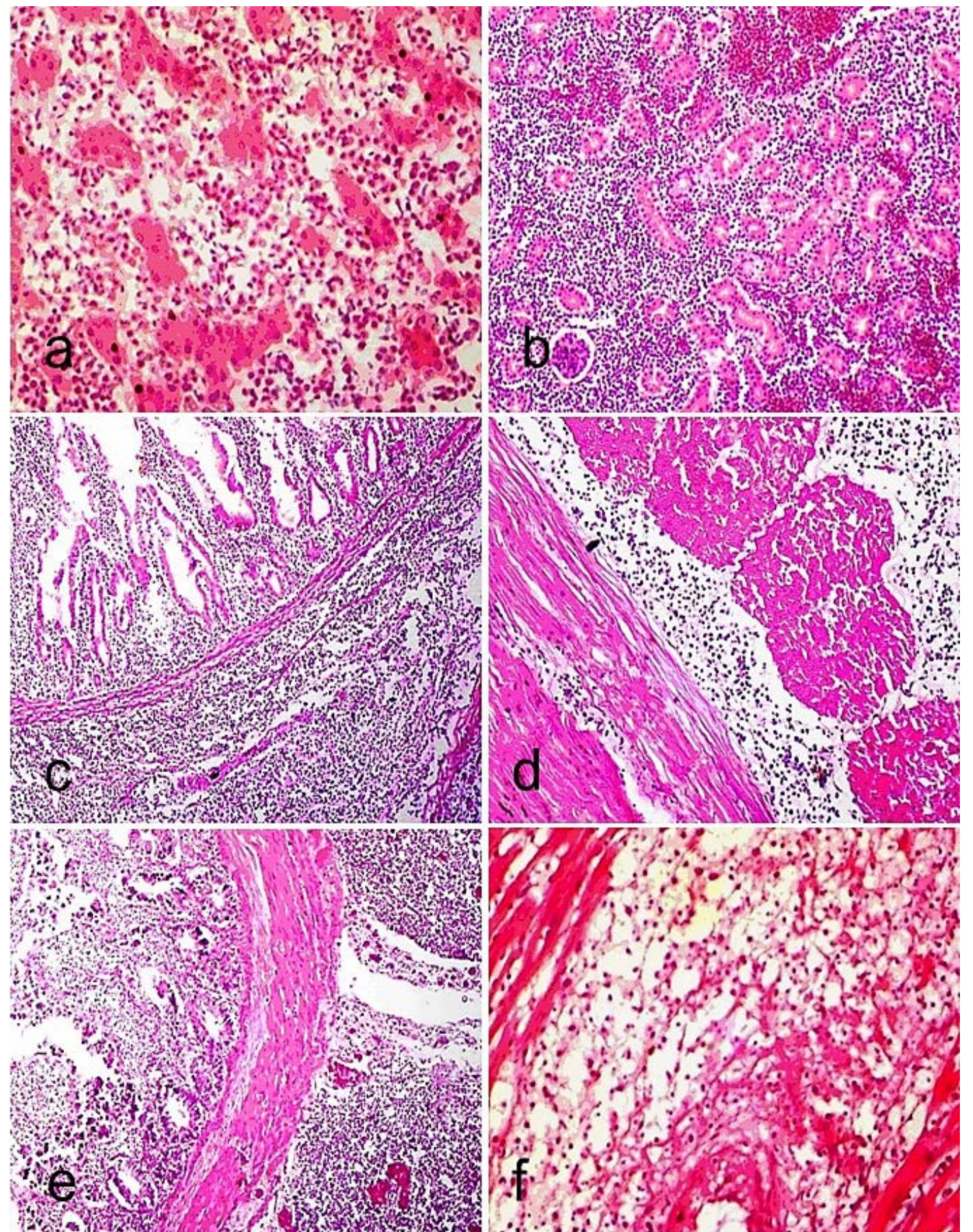

Fig. 2: Section of tissues from chickens with Marek's disease showing extensive proliferation of lymphocytes in the liver (a) and kidney (b), extensive proliferation of lymphocytes in the proventriculus (c-d) and small intestine (e), degeneration of myocardium and infiltration and proliferation of pleomorphic lymphocytes in the heart (f). $\mathrm{H} \& \mathrm{E}$ stain, Objective: 10x (c, e), 20x (a, b, d), 40x (f). 


\section{Histopathological findings}

The findings of histopathology are shown in Fig. 2. Microscopic examinations of affected livers revealed diffuse proliferation of pleomorphic lymphocytes (Fig. 2a). Lymphocyte proliferation was so extensive that the normal architecture of hepatic lobules was largely distorted leaving only islands of hepatic cords. Lymphocyte proliferation was associated with marked haemorrhages and congestion. In the kidney, there was diffuse as well as focal proliferation of pleomorphic lymphocytes in the parenchyma. The infiltrating and proliferating lymphocytic cells destroyed the normal architecture of the kidney (Fig. 2b). In the proventriculus, diffuse and focal proliferation of pleomorphic lymphocytes was observed in the lamina propria, submucosa and between and outside the muscular layers (Fig. 2c-d).In the intestine, focal accumulation of lymphocytes was observed inside the serosal layer, and diffuse proliferation of pleomorphic lymphocytes was seen in the intestinal mucosa (Fig. 2e). Lesions in the myocardium consisted of focal degeneration of muscle cells around blood vessels, associated with diffuse proliferation of small and large lymphocytes (Fig. 2f). In addition, unusual pleomorphism due to the proliferation of neoplastic cells was observed in the spleen.

Here we investigated Marek's disease in chickens from natural outbreaks in commercial poultry in Bangladesh. Tumours were detected in the affected birds. Extensive proliferation of heterogeneous lymphocytes distorting parenchyma was found.

Emaciation, lameness and torticollis were the predominant clinical findings. The clinical and pathological manifestation of MD can be variable in partially protected chickens. Paralysis, chronic wasting, blindness, and fatal lymphoma development in infected, susceptible host birds were reported previously (Davison and Nair, 2004; Jarosinski et al., 2006).

At necropsy, visceral neoplastic lesions were observed most commonly in the proventriculus, followed by liver, spleen, heart, ovary, intestine and kidney; the organs were enlarged, with white large or miliary nodules. Similar lesions were described in other studies (Purchase and Biggs, 1967; Kamaldeep et al., 2007). Infiltration and proliferation of pleomorphic lymphoid cells were observed on histologic examination of the liver, proventriculus, heart, spleen, kidney and intestine. In the liver and kidney, infiltration and proliferation of lymphoid cells were associated with extensive damage in the parenchymatous tissues, along with haemorrhages and congestion. In the heart, focal degenerative and necrotic lesions were seen, along with the infiltration of lymphocytes. In the proventriculus and intestine extensive diffuse as well as focal nodular proliferation of lymphocytes were observed. Changes in the spleen were characterized by unusual pleomorphism of lymphocytes. The lesions were in general consistent with those described by others (Frazier, 1974; Lobago and Woldemeskel, 2004; Goyal et al., 2006). Although clinical disease with paralysis of legs and wings, higher than normal mortality with gross lesions of tumours in multiple organs, and enlarged peripheral nerves is often sufficient to make a positive diagnosis, the confirmatory diagnosis should be based on histopathology. 
In conclusion, it is suggested that Marek's disease can be expected in poultry farms without obvious nervous involvement and the lymphomatous lesions may be diverse, depending on the tissues involved.

\section{References}

Churchill AE, Payne LN, Chubb RC 1969: Immunization against Marek's disease using a live attenuated virus. Nature 221 744-747.

Davison F, Nair VK (Eds) 2004: Marek's disease: An Evolving Problem. Elsevier Press, Amsterdam. The Netherlands and Boston, USA.

Frazier JA 1974: Ultrastructure of lymphoid tissue from chicks infected with Marek's disease virus. Journal of National Cancer Institute 52 829-837.

Goyal D, Singh A, Sood N, Gupta K, Sood NK 2006: Adenocarcinoma of liver with Marek's disease in poultry. Indian Veterinary Journal 83 562-563.

Jarosinski KW, Tischer BK, Trapp S, Osterrieder N 2006: Marek's disease virus: lytic replication, oncogenesis and control. Expert Review of Vaccines 57 61-772.

Jarosinski, KW 2017: Interindividual spread of herpesviruses. Advances in Anatomy, Embryology, and Cell Biology 223 195-224.

Kamaldeep P, Sharma C, Jindal N, Narang G 2007: Occurrence of Marek's disease in vaccinated poultry flocks of Haryana (India). International Journal of Poultry Science 6 372-377.

Lobago F, Woldemeskel M 2004: An outbreak of Marek's disease in chickens in central Ethiopia. Tropical Animal Health and Production 36 397-406.

Luna LG 1968: Manual of histopathologic staining methods of the armed forces institute of pathology, $3^{\text {rd }}$ edn. McGrow, Hill Book Company, London.

Moslehuddin, Dewan ML 1974: Incidence and diagnosis of Marek's disease in two poultry farms of Bangladesh. Bangladesh Veterinary Journal 8 45-48.

Nair, V 2018: Spotlight on avian pathology: Marek's disease. Avian Pathology 47 440-442.

Purchase HG, Biggs PM 1967: Characterization of five isolates of Marek's disease. Research in Veterinary Science 8 440-449.

Rispens BH, Van Vloten J, Mastenbroek N, Maas HJL, Hendrick JL 1972: Control of Marek's disease in the Netherlands. II. Field trials on vaccination with an avirulent strain (CVI 988) of Marek's disease virus. Avian Diseases 16 126-138.

Schat KA, Nair V 2013: Neoplastic diseases: Marek's disease. In DE Swayne, JR Glisson, LR McDougald, LK Nolan, DL Suarez, \& VL Nair (Eds.), Diseases of Poultry $13^{\text {th }}$ edn. Hoboken, NJ: Wiley-Blackwell. pp. 515-552.

Silva RF 1992: Differentiation of pathogenic and non-pathogenic serotype 1 Marek's disease viruses (MDVs) by the polymerase chain reaction amplification of the tandem direct repeats within the MDV genome. Avian Diseases 36 521-528.

Witter RL 1997: Increased virulence of Marek's disease virus field isolates. Avian Diseases 41 149-163. 